\title{
OPTIMIZATION AND ENERGY SAVING WHEN CHOOSING THE SITE OF INSTALLATION OF A CRUSHING STATION IN A MOUNTAINOUS TERRAIN CASE OF THE DJBEL EL BORDJ CAREER, SIDI BELABBAS, ALGERIA
}

\author{
RACHID KHEBBAB ${ }^{1}$, SAMIR REMLI ${ }^{2,3}$, ISSAM ROUAIGUIA ${ }^{2}$, AISSA \\ BENSELHOUB $^{* 4}$ \\ ${ }^{I}$ Mining Department, Earth Sciences Faculty, Badji Mokhtar University, Annaba, Algeria \\ ${ }^{2}$ Laboratory of Mining Resources Valorization and Environment, Badji Mokhtar University, \\ Annaba, Algeria \\ ${ }^{3}$ Mining engineering department - Larbi Tebessi University, Tebessa, Algeria \\ ${ }^{4}$ State Agrarian and Economic University, Dnipro, Ukraine
}

\begin{abstract}
In open pit or underground mines and quarries, especially in mountainous terrain, the choice of the perfect place to install a crushing station requires a decision finalized by a detailed study of the areas close to the quarries such as the water drainage, the morphology of the deposit, the installed capacity, the opening mode of the deposit etc. For this purpose, in this article we will propose an installation of the crushing station of the quarry Djbel El Bordj which serves to save energy throughout the life of the quarry, and also will gain the transportation distance of the stones that determines the number of dumpers needed for planned production.
\end{abstract}

Keywords: aggregate quarry, energy saving, conveyor belt, crushing station, optimization.

\section{INTRODUCTION}

Aggregates are usually defined as hard granular materials used in construction, and which may be natural, manufactured, or recycled [1]. Natural (or primary) aggregate is obtained from mineral sources subject only to processing through crushing and sizing. Manufactured (or secondary) aggregate is of mineral origin, but which has resulted from industrial processes, such as furnace slag. Recycled aggregates result from the processing of inorganic materials previously used in construction, for instance construction and demolition waste. Also the Aggregates (stone crusher) are one such industry that exists in the vicinity of almost all major cities/towns throughout the country in all the states because the construction activities go on throughout the country [2]. As transportation of stone over long distances adds to cost of the crushed stone products, the crushers need to be necessarily located nearer to the demand centers such as Cities, Bridges, and Canals etc. Stone Crushers also need electricity supply and large number of man power for its operation. It also needs access roads for the movement of mined stone as well as crushed stone products. It is for these reasons that most Stone Crushers are located along the periphery of Cities or in the vicinity of major construction projects. In most cases, the Stone Crushers come up in clusters of number of units ranging from five to fifty in one cluster. The crushers are

\footnotetext{
*Corresponding author, email: benselhoub@yahoo.fr
}

(C) 2016 Alma Mater Publishing House 
located nearer to the source of raw material such as Stone mines, River Beds etc. The absence of natural aggregate at cost-effective transportation distances has prompted extensive use of manufactured aggregates [3]. The US aggregate industry produces $\sim 1.1$ billion tons of crushed stone per year with carbonates and granites accounting for $71 \%$ and $16 \%$, respectively [4]. The extensive use of manufactured aggregates has required proper modification of characterization, design and construction practices. In addition, it has motivated studies to reduce energy consumption, to attain optimal crusher design and operation, and to minimize waste. Aggregate manufacturing typically starts by blasting rock masses and is followed by a series of crushing stages. In addition, Crushing is the process of reducing blasted rocks into smaller sizes needed for use such as in construction of bridges, tunnels; roads and building activities [5].

Crushing of fragmented rocks is unit of communition and particle sizing. The crushing plant is an assemblage of primary crusher and secondary crusher. The following product sizes (granite) can be obtained by methods of screening immediately after crushing [6].

Also, the construction aggregates sector is an important part of most modern developed economies. For example in the UK, aggregates account for approximately $85 \%$ of the non-energy minerals extracted. They are essential for constructing and maintaining what is literally the physical framework of the buildings and infrastructure on which our society depends. To ensure that construction aggregates are fit for purpose and meet the requirements of the enduses, it is important to have an understanding of the geology of the resources, production processes, and standards and test methods used to evaluate their suitability. Construction aggregate is normally defined as being hard, granular materials, which are suitable for use either on their own or with the addition of cement, lime or a bituminous binder in construction. Important applications include concrete, mortar, road stone, asphalt, railway ballast, drainage courses and bulk fill. There are three main types: natural aggregate (from mineral sources with nothing more than physical processing, often referred to as 'primary aggregate'), manufactured aggregate (derived from industrial processes as a by-product, often referred to as 'secondary aggregate') and recycled aggregate (British Geological Survey [7].

Rock mechanical preparation is the second phase after the exploitation. The rock needs, according to the demand of the granulometry of primary crushing then secondary thanks of the conveyors, then screens and sometimes even a tertiary one. The classical fragmentation modes involve subjecting the solid to be fragmented to a constraint created by contact forces [8].

Conveyors increase efficiency when properly used to transport material from one section of the plant to another [9]. They can be used as inputs to hoppers or they can be used to transport finished materials to trucks or stockpiles. The conveyor's efficiency is determined by belt speed, proper loading techniques, and correct incline selection based on the type of material being transported. Hence the importance of specialized computer tools that allow in addition to the search for a solution "optimal" through the simulation of several scenarios, to benefit from the knowledge and skills of designers in a particular operational area, such as sizing conveyors [10].

Our study is used to choose the most economical site for the Sarl Djebel El Bordj quarry which is located in a mountainous relief, therefore thanks to the geometry of each equipment; the station will be installed after the preparation of the ramp in the hillside of the relief by the digging of the half-trenches in the form of benches, the height and the width of these are different according to the geometry of each equipment that will be installed.

\section{GEOLOGY OF AGGREGATE RESOURCES}

Any naturally occurring geological material can be used as construction aggregate as long as it satisfies the requirements of the end-use specification. Primary aggregates are produced from two main sources, 'crushed rock' and sand and gravel. Crushed rock aggregate is produced from hard, strong rock formations including igneous (andesite, basalt, diorite, dolerite, gabbro, granite, rhyolite, tuff), metamorphic (hornfels, gneiss, quartzite, schist) and sedimentary (sandstone, limestone) rock. Most limestone's and dolomites are hard and durable and useful for aggregate. The quality of the limestone resources and their ease and economy of working may be affected by a number of geological factors such as waste content, dolomitisation and degree of faulting and folding. The suitability of sandstone for aggregate use depends on its strength, porosity and durability. Many types of sandstone are too porous and weak to be used other than as sources of constructional fill. In general, older more indurated sandstones exhibit higher strengths and are suitable for more demanding aggregate uses. Igneous rocks tend to produce strong aggregates with a degree of skid resistance and are hence suitable for many 
road surfacing applications, as well as for use in the lower parts of the road pavement. The high strength and attrition resistance of certain igneous rocks results in their use as railway ballast [7]. Sand and gravel deposits are accumulations of the more durable rock fragments and mineral grains, which have been derived from the weathering and erosion of hard rocks mainly by glacial and river action, but also by wind. The term 'gravel' ("coarse aggregate") is used to define particles between 4 and $80 \mathrm{~mm}$ and the term "sand' ("fine aggregate") for material that is finer than $4 \mathrm{~mm}$, but coarser than $0.063 \mathrm{~mm}$. The properties of gravel, and to a lesser extent sand, largely depend on the properties of the rocks from which they were derived. However, water action is an effective mechanism for wearing away weaker particles, as well as separating different size fractions. Most sand and gravel is composed of particles that are durable and rich in silica (quartz, quartzite and flint). Other rock types, mainly limestone, may also occur in some land-won deposits including deleterious impurities such as lignite, mudstone, chalk and coal [7].

\subsection{Location of the quarry and installed capacity}

The Sarl Djbel El Bordj quarry located in Sidi Ali Benyoub, Si Belabbas Algeria, which is a limited liability company, with a projected production of 900000 tones/year, the crushing station of aggregate is part of this society witch product a different fraction $(0-3,3-8,8-15,15-25$..., etc.) with a theoretical yield of 250 tons/hour.

\section{MATERIALS AND METHODS}

Generally, the installation of the conveyors of the station will be carried out with inclinations of each one in the case where the site is folded. So their elevations and lengths are determined by the height of the equipment installed soon, also to consider the slip of the flow (Figure 1).

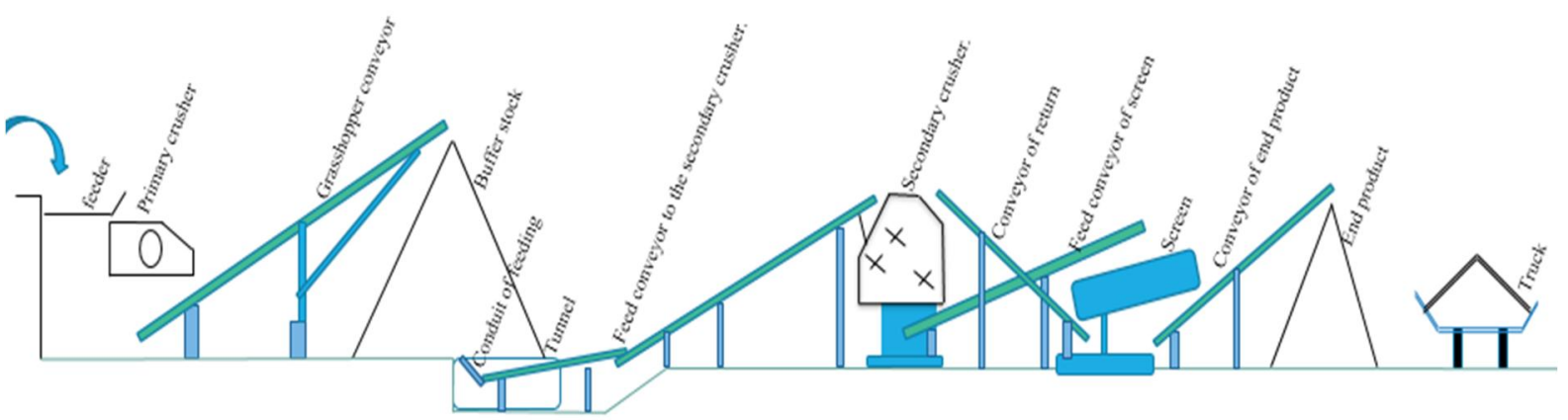

Fig. 1. Side view schema of the crushing installation station in a horizontal platform I1.

From the geological study of the deposit, the stratification of the limestone layer in the Sarl Djbel El Bordj quarry is located between the level $900 \mathrm{~m}$ to the top of the mountain, while under this last up to a low level 780 $\mathrm{m}$ which contains yellow and gray marl, so it is proposed to install this station in the lower part of the mountain which represents an area devoid of useful material for this company.

Then the preparation of the installation site is carried out in the hillside of the relief, the latter is graduated according to each geometry of equipment.

\section{RESULTS AND DISCUSSION}

When the site is already prepared with benches which is illustrated in Figure 2, it is also proposed to install the conveyors in a horizontal position in order to save more energy consumed when transporting the equipment material to the other, therefore the latter breaks the conditions for the determination of the conveyor length cited above which due to a possibility for minimizing the length of that Figure 3 which leads to the reduction of the driving force and of course a decrease in power of asynchronous motor. But this proposal does not apply where there is a return of the product to the previous equipment, so in our case, the secondary crusher and the screen are installed in the same level; because the refusal of screening will return to reduce its grain size to that desired.

So, to determine all these advantages, a numerical simulation was carried out with the help of an online tool "Tecnitude" used to size the conveyors, he proposes us to use this calculation form to help us in the technical 
definition of our conveyor belt. Depending on the load we have to transport, this tool allows us to determine the power of the motor of our conveyor in both situations (the angles $0^{\circ}$ and $17.5^{\circ}$ ).

We took into account two different situations, then we made the necessary calculations for each case, from which we draw the necessary interpretation.

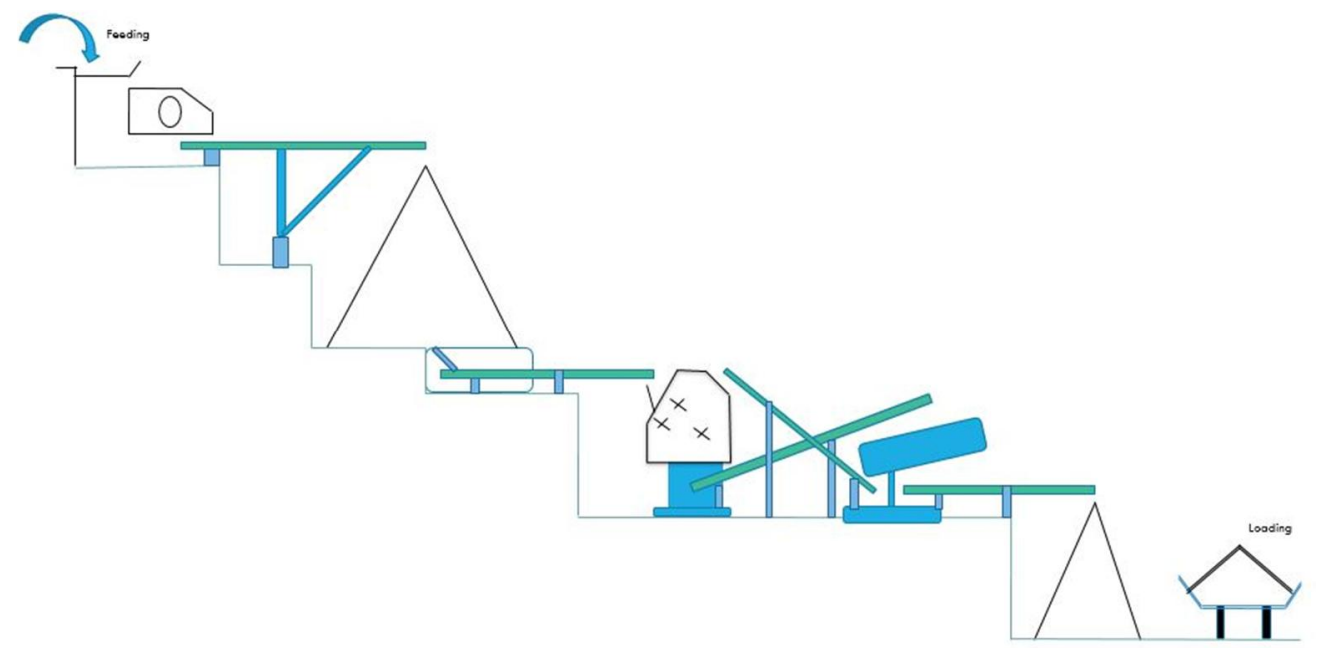

Fig. 2. Schema of side view of the crushing station in graduated platforms (benches) I2.

First situation: Consider the case where the station is installed on a horizontal platform I1. For determining the motor power, the grasshopper conveyor is taken into consideration. The latter works with an inclination angle of $17.5^{\circ}$.

The conveyor shown in Figure 3 having the following data: length $\mathrm{L}=30 \mathrm{~m}$; width of the band: $0.8 \mathrm{~m}$; drum diameter: $0.4 \mathrm{~m}$.

The conveyor equipped with a counter weight, its hourly production is $260 \mathrm{t} / \mathrm{h}$ and its speed is $1 \mathrm{~m} / \mathrm{s}$.

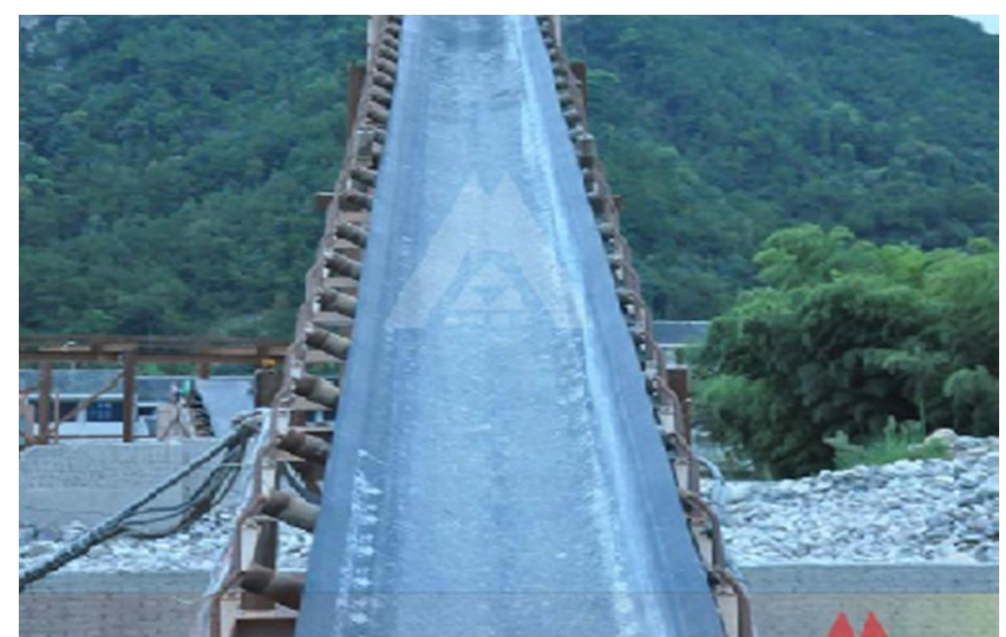

Fig. 3. Photography of a band conveyor.

The tool "Tecnitude" gave us the results as follows: 

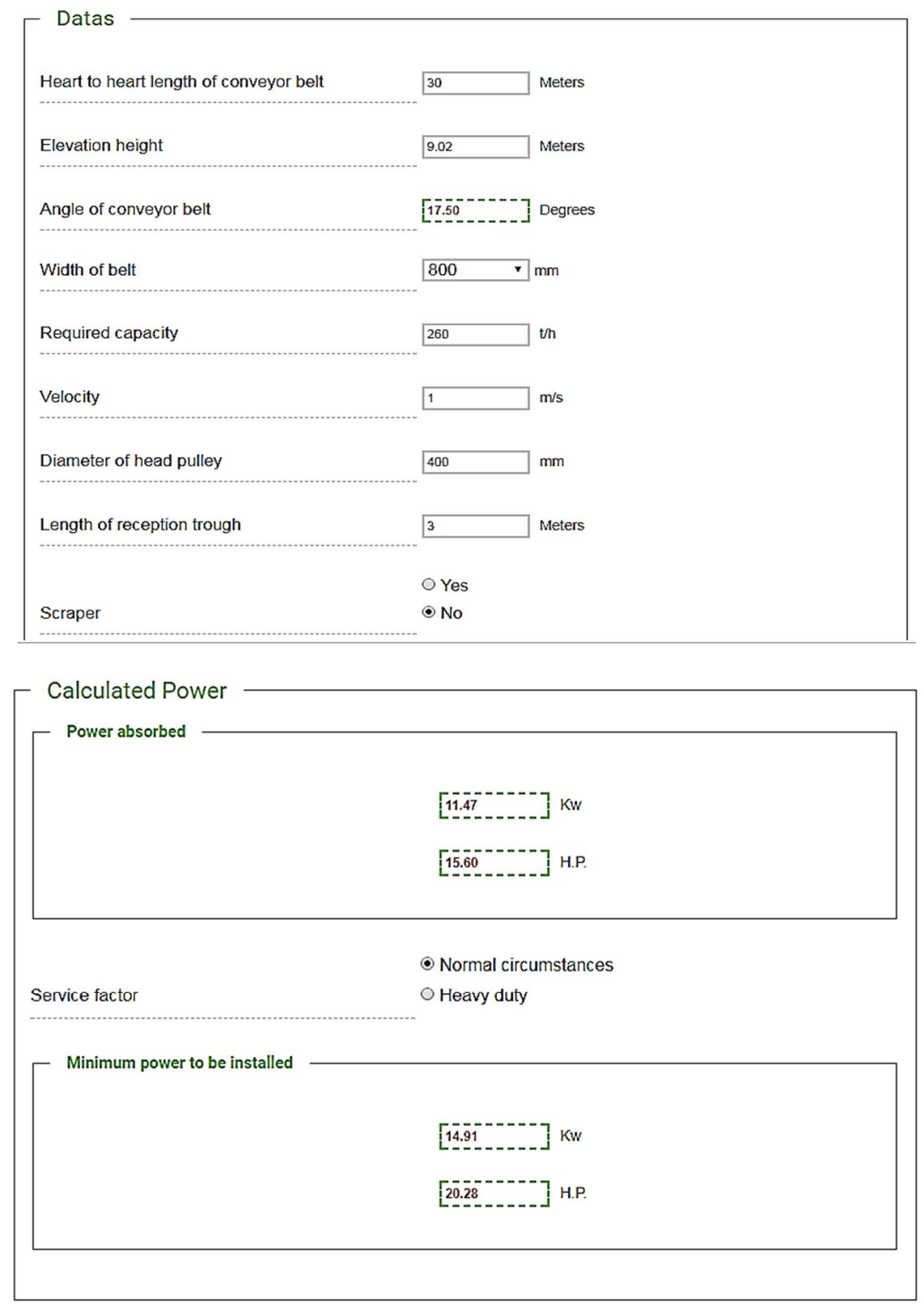

$\left[\begin{array}{l}\text { Technical information } \\ \text { Rotation speed of the head pulley }\end{array}\right.$

$\left[\begin{array}{ll}\text { Calculation of the tension in the belt } & \\ \text { Tension type } & \begin{array}{l}\text { OWith screw } \\ \odot \text { With counter weight }\end{array} \\ \text { Tension of the belt } & \end{array}\right.$


Second situation: The station is installed on the hillside, the conveyors work horizontally $\left(\beta=0^{\circ}\right)$, the determination of the motor power for the same conveyor is redone. Then from the Figure 4 we have the angle of the grasshopper conveyor $\beta=17.5^{\circ}$ and its length $L=30 \mathrm{~m}$. In this case, we can express the length $L^{\prime}$ which represents the installation of the conveyor for $\mathrm{I} 2: L^{\prime} \cos 17.5^{\circ}=28.61 \mathrm{~m}$.

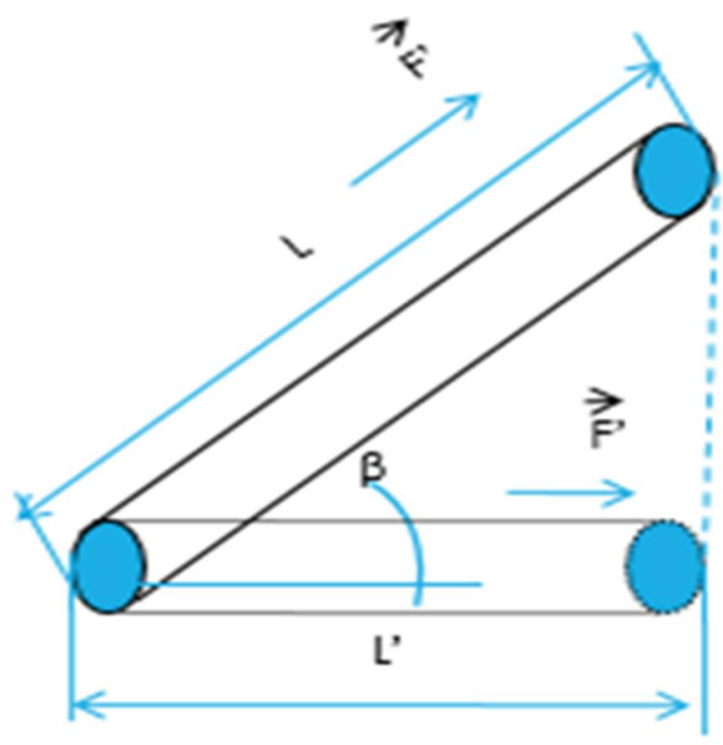

Fig. 4. Schema conveyor inclination for both cases (angles $0^{\circ}$ and $17.5^{\circ}$ ).

We can also minimize the length of the grasshopper conveyor for the I2 Schema because it is independent of the height of the equipment, so it is enough to give a space between the equipment for the cleaning during the production and to ensure the balancing of the one in failover case. Indeed, to keep the same amount of storage of the product in the pre-stock as the crushing Schema I1, we take the length of the conveyor $25 \mathrm{~m}$ Figure 5.

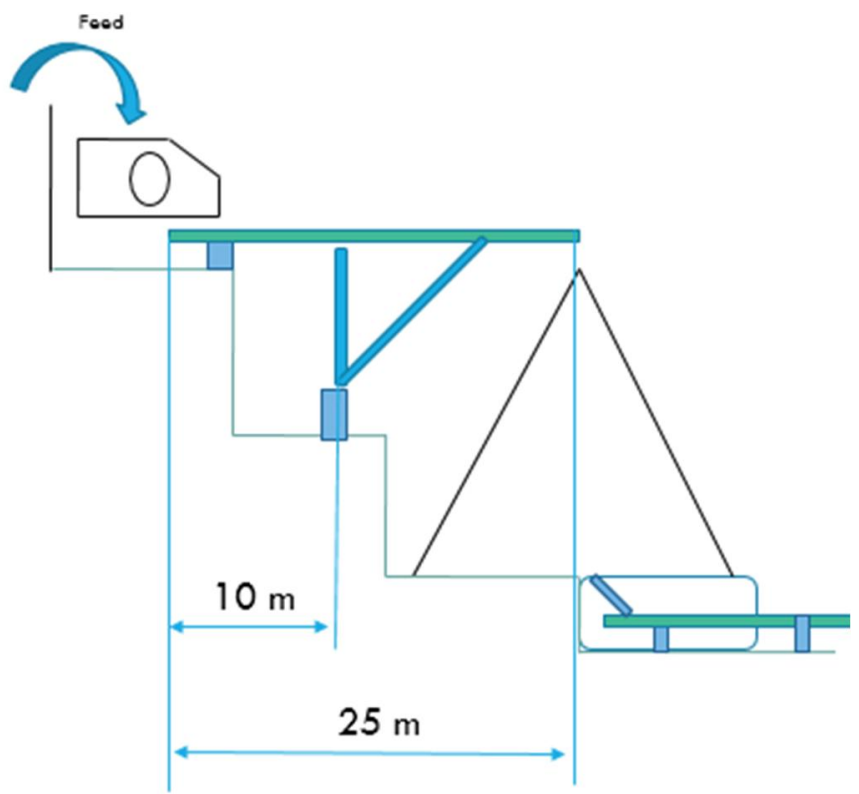

Fig. 5. Installation schema of the grasshopper conveyor.

Therefore, we will have the results obtained by the tool as follows: 


\begin{tabular}{|c|c|c|}
\hline Heart to heart length of conveyor belt & 25 & Meters \\
\hline Elevation height & 0 & Meters \\
\hline Angle of conveyor belt & $0.00^{---}$ & Degrees \\
\hline Width of belt & 800 & mm \\
\hline Required capacity & 260 & th \\
\hline Velocity & 1 & $\mathrm{~m} / \mathrm{s}$ \\
\hline Diameter of head pulley & 400 & $\mathrm{~mm}$ \\
\hline Length of reception trough & 3 & Meters \\
\hline & OYes & \\
\hline Scraper & $\odot$ No & \\
\hline
\end{tabular}

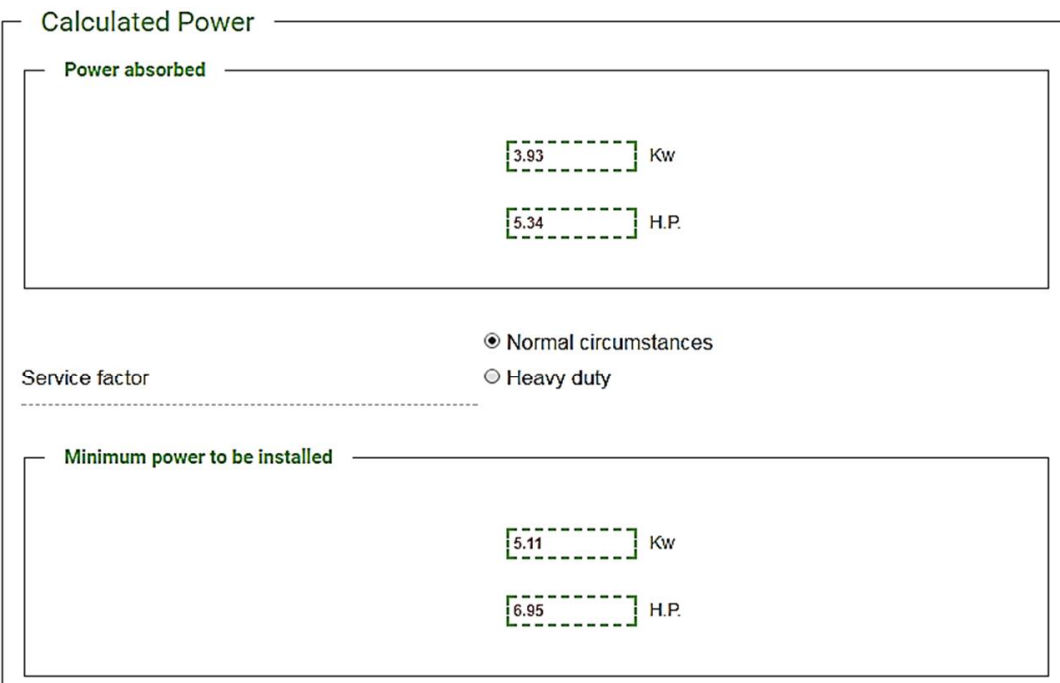

\begin{tabular}{|c|c|}
\hline Rotation speed of the head pulley & {$[47.75-\cdots] \mathrm{rev} / \mathrm{min}$} \\
\hline Reducer drive couple & {$[1021 \cdots-\cdots \mathrm{Nm}$} \\
\hline
\end{tabular}

$\left[\begin{array}{ll|}\text { Calculation of the tension in the belt } & \\ \text { Tension type } & \odot \text { With screw } \\ \text { Tension of the belt } & \end{array}\right.$


The results obtained by the tool "Tecnitude" helps us to compare between the two cases, so they suggest that the conveyor where the angle $17.5^{\circ}$ and its length $30 \mathrm{~m}$ requires a minimum installed motor power of $14.91 \mathrm{~kW}$, contrariwise the second where the angle of the conveyor $0^{\circ}$ and its length $25 \mathrm{~m}$ requires a minimum power of $5.11 \mathrm{~kW}$, so an optimization of consumption of electrical energy to $65.7 \%$, and then the difference in position of the conveyor generates a difference also the values of band tension between them $(23.6 \mathrm{daN} / \mathrm{cm}$ and $69 \mathrm{daN} / \mathrm{cm})$ which will influence on its life.

The knowledge of the total height $\mathrm{Ht}$ gained has allowed us to express the distance of the transport connecting the deposit and the crushing station which depends essentially on the sum of the heights of the equipment to be installed and the stocks (in the case where the installation of several equipment in the same level, we take the height of the first one which is located right next to the front of the bench), so we establishe the following relation:

$$
H_{t}=\frac{H_{s}+H_{p s}+H_{f p}+H_{s c}}{m}
$$

Where: $H_{s}$ is the height of sail (m), $H_{p s}$ is the height of pre stock $(\mathrm{m}), H_{s c}$ is the height of secondary crusher $(\mathrm{m}), H_{f p}$ is the height of the finished product (m).

\section{CONCLUSIONS}

The installation of the crushing station equipment in benches where the relief is mountainous gives significant results compared to the installation of that in a same platform, which due to a reduction of the cost of work, which will decrease the return price of one ton of aggregates. However, there is a bit of ancillary work such as preparing the banquettes, which are in the hillside of the relief. On the other hand the main advantages for this installation are:

1) Decrease in the energy consumed by the conveyors.

2) Reducing the length of the conveyor and the wear of the belt.

3 ) Reduction of the losses of the material of its overflow during its horizontal movement.

4) Ease and speed of installation of civil works and infrastructure.

5) Reduction of the necessary number of dumpers intended for the satisfaction of the projected production.

\section{REFERENCES}

[1] https://www.dorsetforyou.gov.uk/media/223980/Local-Aggregates-Assessment-LAA---2012/pdf/LAA_2012 -_FINAL.pdf.

[2] http://cpcbenvis.nic.in/scanned\%20reports/COMP_IND_STONE_CRUSHER_REPORT.pdf.

[3] Guimaraes, M.S., Valdes, J.R., Palomino, A.M., Santamarina, J.C., Aggregate production: Fines generation during rock crushing, International Journal of Mineral Processing, vol. 81, 2007, p. 237-247.

[4] http//:www.usgs.gov/ minerals/pubs/commodity/myb.

[5] Hardin, B.O, Crushing of Soil Particles, Journal of Geotechnical and Geoenvironmental Engineering, vol. 111 no. 10,2001 , p. 1177 - 1192.

[6] Afeni, T.B., Cost evaluation of producing different aggregate sizes in selected quarries in Ondo State Nigeria, International journal of engineering and advanced technology studies, vol.4, no.2, 2016, p. 6-19.

[7] https://www.bgs.ac.uk/downloads/start.cfm?id=1355.

[8] Rapport DB Sarl Djebel El Bordj, 2012.

[9] http://navybmr.com/study\%20material/14080a/14080A_ch6.pdf.

[10] Aomar, I., Abdelhakim, R., Optimisation du temps productif: exploitation des outils informatiques de dimensionnement, La revue ivoirienne des sciences et technologie, 2008, p. $11-26$. 